Published in final edited form as:

J Gastrointest Surg. 2012 January ; 16(1): 104-112. doi:10.1007/s11605-011-1754-9.

\title{
RAGE Gene Deletion Inhibits the Development and Progression of Ductal Neoplasia and Prolongs Survival in a Murine Model of Pancreatic Cancer
}

\author{
Joseph DiNorcia \\ College of Physicians and Surgeons, Department of Surgery, Columbia University, 161 Fort \\ Washington Avenue, Suite 820, New York, NY 10032-3784, USA \\ Minna K. Lee \\ College of Physicians and Surgeons, Department of Surgery, Columbia University, 161 Fort \\ Washington Avenue, Suite 820, New York, NY 10032-3784, USA \\ Dorota N. Moroziewicz \\ College of Physicians and Surgeons, Department of Surgery, Columbia University, 161 Fort \\ Washington Avenue, Suite 820, New York, NY 10032-3784, USA
}

\section{Megan Winner}

(C) 2011 The Society for Surgery of the Alimentary Tract

jda13@columbia.edu.

This manuscript received a first-place basic science plenary award at the 26th Annual Residents and Fellows Research Conference and was presented at the SSAT Meeting in Chicago, May 2011.

Discussant

Dr. Emina H. Huang (Gainesville, FL): Congratulations, Dr. DiNorcia, for continued excellent work under the guidance of Drs. Ann Marie Schmidt and John Allendorf. Your presentation today is the culmination of a tremendous labor of breeding, genotyping, and pathologic dissection and you are commended for your efforts.

In your discussion, you refer to the issues that mechanism in your studies is only inferred. With the recent advances in combining molecular pathways and signatures from malignancies such as melanoma and non-small cell lung cancer in efforts to provide targeted treatment, I have three questions:

1. Are either soluble RAGE or a RAGE small molecule inhibitor, or cromolyn or other S100P antagonists potential treatments for pancreatic cancer?

2. Have you tried these interventions early on in the Tuveson mouse model?

3. Do you see a role for RAGE antagonism in those kindred with a familial pancreatic cancer or for those lacking metastatic disease, to prevent either metastases or recurrence?

Again, brilliant work and congratulations!

Closing Discussant

Dr. Joseph DiNorcia: Thank you, Dr. Huang, for your gracious comments and questions. RAGE inhibitors may be potential treatments for pancreatic cancer. It also is possible to envision inhibitors of downstream signaling as potential treatments once these post-receptor pathways are better defined. Given the complex role RAGE plays in differentially regulating cell survival and cell death, we have considerable more work to do prior to clinical application.

Targeting the ligand-RAGE axis also may be a strategy to improve the effectiveness of chemotherapy. For example, it has been shown that HMGB1 is released following tumor cell death and interacts with RAGE on neighboring tumor cells to promote survival. By inhibiting this ligand-RAGE interaction, we might be able to enhance a chemotherapeutic agent's ability to kill tumor cells. We have treated a very small number of $P d x 1$-Cre; Kras $G 12 D /+;$ p16Ink4a-l- mice with sRAGE. Although we noted no differences in the incidence of carcinoma, there was a significantly decreased stromal reaction in sRAGE-treated mice compared to controls, suggesting that stromal cells play roles in tumorigenesis via RAGE-dependent pathways.

Finally, perhaps the most practical clinical application of RAGE antagonism is in pancreatic cancer prevention. For example, RAGE inhibition in patients with IPMN may delay or arrest tumor progression to carcinoma. Or, in patients with localized pancreatic cancer, RAGE antagonism may prevent invasion and metastases by inhibiting tumor cell adhesion and motility. The ligand-RAGE axis is an attractive target for potential prophylaxis and treatment of pancreatic cancer and thus remains an exciting area for further study. 
College of Physicians and Surgeons, Department of Surgery, Columbia University, 161 Fort Washington Avenue, Suite 820, New York, NY 10032-3784, USA

\title{
Paritosh Suman
}

College of Physicians and Surgeons, Department of Surgery, Columbia University, 161 Fort Washington Avenue, Suite 820, New York, NY 10032-3784, USA

\section{Fei Bao}

College of Physicians and Surgeons, Department of Pathology, Columbia University, New York, NY, USA

\author{
Helen E. Remotti \\ College of Physicians and Surgeons, Department of Pathology, Columbia University, New York, \\ NY, USA
}

\section{Yu Shan Zou}

Langone Medical Center, Department of Medicine, New York University, New York, NY, USA

\section{Shi Fang Yan}

Langone Medical Center, Department of Medicine, New York University, New York, NY, USA

\section{Wanglong Qiu}

College of Physicians and Surgeons, Department of Otolaryngology and Head and Neck Surgery, Columbia University, New York, NY, USA

\section{Gloria H. Su}

College of Physicians and Surgeons, Department of Surgery, Columbia University, 161 Fort Washington Avenue, Suite 820, New York, NY 10032-3784, USA

College of Physicians and Surgeons, Department of Otolaryngology and Head and Neck Surgery, Columbia University, New York, NY, USA

\section{Ann Marie Schmidt}

Langone Medical Center, Department of Medicine, New York University, New York, NY, USA

\section{John D. Allendorf}

College of Physicians and Surgeons, Department of Surgery, Columbia University, 161 Fort Washington Avenue, Suite 820, New York, NY 10032-3784, USA

\section{Abstract}

Background-The receptor for advanced glycation end-products (RAGE) is implicated in pancreatic tumorigenesis. Activating Kras mutations and p16 inactivation are genetic abnormalities most commonly detected as pancreatic ductal epithelium progresses from intraepithelial neoplasia (PanIN) to adenocarcinoma (PDAC).

Objective-The aim of this study was to evaluate the effect of RAGE (or AGER) deletion on the development of PanIN and PDAC in conditional $\mathrm{Kras}^{G 12 D}$ mice.

Materials and Methods-Pdxl-Cre; $L S L-K r a s{ }^{G 12 D /+}$ mice were crossed with $R A G E^{-/-}$mice to generate Pdxl-Cre; LSL-Kras ${ }^{G 12 D /+} ;$ RAGE $^{-/-}$mice. Pdxl-Cre $;$LSL-Kras ${ }^{G 12 D /+} ;$ pl6 $^{\text {Ink4a-l- }}$ mice 


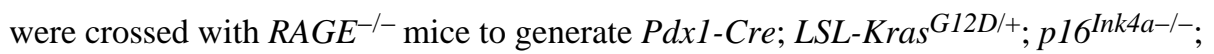
$R A G E^{-/-}$mice. Pancreatic ducts were scored and compared to the relevant $R A G E^{+/+}$controls.

Results-At 16 weeks of age, $\mathrm{Pdxl-Cre} ; \mathrm{LSL}-\mathrm{Kras}^{\mathrm{G12D/+}} ; \mathrm{RAGE}^{-/-}$mice had significantly fewer high-grade PanIN lesions than Pdxl-Cre; LSL-Kras ${ }^{G 12 D /+} ; R A G E^{+/+}$controls. At 12 weeks of age, none of the Pdxl-Cre; LSL-Kras ${ }^{G 12 D /+} ;$ pl $^{\text {Ink4a-l-}} ; R_{A G E^{-/-}}$mice had PDAC compared to a $45.5 \%$ incidence of PDAC in PdxI-Cre; LSL-Kras ${ }^{G 12 D /+} ; p_{16}^{\text {Ink } 4 a-/-} ; R A G E^{+/+}$controls. Finally, Pdxl-Cre; LSL-Kras ${ }^{G 12 D /+} ;$ pl $^{\text {Ink } 4 a-/-} ; R A G E^{-/-}$mice also displayed markedly longer median survival.

Conclusion-Loss of RAGE function inhibited the development of PanIN and progression to PDAC and significantly prolonged survival in these mouse models. Further work is needed to target the ligand-RAGE axis for possible early intervention and prophylaxis in patients at risk for developing pancreatic cancer.

\section{Keywords}

RAGE; AGER; PanIN; Pancreatic adenocarcinoma; Pancreatic cancer; Pdxl-Cre; Kras; p16; $R A G E^{-/-}$mice

\section{Introduction}

Pancreatic cancer is one of the most lethal gastrointestinal malignancies and the fourth leading cause of cancer-related deaths in the USA. ${ }^{1}$ The overall incidence and mortality have changed little in the past three decades with estimates of 43,140 new cases and 36,800 deaths from the disease in 2010 . Estimated 5-year survival is approximately $5 \%$ in part because the disease is diagnosed at late stages when it is no longer amenable to curative resection. Thus, there is a need to identify novel targets for early intervention in pancreatic cancer.

Pancreatic ductal adenocarcinoma (PDAC) is thought to follow an adenoma-carcinoma sequence, arising from noninvasive precursor lesions called pancreatic intraepithelial neoplasia (PanIN) and progressing through increasingly severe stages of cellular atypia to invasive PDAC. ${ }^{2}$ On the molecular level, these lesions show multi-step changes that include early activating mutations in the proto-oncogene, $K R A S$, and subsequent inactivating mutations in tumor-suppressor genes such as $p 16^{I N K 4 A} .3$ The central role of these genetic alterations is evidenced by the presence of mutations in KRAS and inactivating mutations in p16 $6^{I N K 4 A}$ in over $90 \%$ of cases of human PDAC.,

In this context, the preclinical study of PanIN progression to PDAC has been made possible by genetically modified mouse models that recapitulate human pancreatic neoplasia on both genetic and histomorphologic levels. The conditional Kras ${ }^{G 12 D}$ model employs Cre-Lox recombination to create murine pancreatic ductal lesions that closely resemble human PanINs. In brief, the mouse genomic Kras is engineered to contain a G to A transition in codon 12 that results in a glycine to aspartic acid substitution in the expressed protein and subsequent constitutive downstream signaling of Ras effector pathways. ${ }^{4}$ A Lox-STOP-Lox $(L S L)$ construct upstream from the modified Kras locus silences the mutation. When 
interbred with mice that express Cre recombinase under the pancreas-specific promoter, $P d x 1$, the silencing cassette is excised, resulting in expression of the mutant Kras allele and development of early PanIN lesions. The additional knockout of $p 16^{\operatorname{Ink} 4 a}$ causes more rapid development of PanIN and PDAC and allows for the study of progression from noninvasive to invasive pancreatic ductal disease ${ }^{5-7}$ (Qiu et al.; manuscript in revision). The conditional $\operatorname{Kras}^{G 12 D}$ model thus is a valuable tool to explore possible novel targets for early intervention in pancreatic cancer.

One such target is the receptor for advanced glycation end-products (RAGE). RAGE is a multi-ligand, transmembrane cell surface receptor of the immunoglobulin superfamily whose ligands include S100 proteins and high-mobility group box-1 (HMGB1). ${ }^{8}$ LigandRAGE interactions lead to initiation of downstream signaling pathways that perpetuate inflammation, promote cell survival, and inhibit cell death. ${ }^{9}$ The ligand-RAGE axis thus has been linked to carcinogenesis. ${ }^{10-17}$ Recent work with RAGE and pancreatic cancer has identified the ligand-RAGE axis as a promising target for intervention in this disease. RAGE and its ligands have been shown to be over-expressed in human PDAC and to correlate with tumor proliferation and invasiveness. ${ }^{13,18-20}$ Expression of S100 proteins, for example, increases as ductal lesions progress from PanIN to PDAC. ${ }^{21}$ Furthermore, release of HMGB1 from pancreatic tumor cells has been shown to enhance tumor cell survival via a RAGE-dependent pathway. ${ }^{9}$

Together, these data suggest that the ligand-RAGE axis plays an important role in the development and progression of pancreatic cancer. We previously reported that genetic deletion of RAGE significantly inhibited tumorigenesis and progression to invasive disease in a mouse model of colorectal carcinoma. ${ }^{22}$ In the present study, we describe the potential benefit of loss of RAGE function in inhibiting PanIN development and progression to PDAC in a conditional Kras ${ }^{G 12 D}$ mouse model.

\section{Materials and Methods}

\section{Animals}

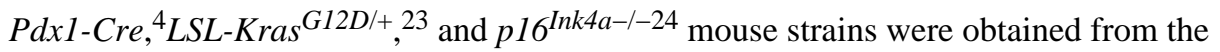
National Cancer Institute Mouse Repository (Frederick, MD). RAGE knock-out $\left(R A G E^{-/-}\right)$ mice were generated in the C57BL/6 background as described previously. ${ }^{25,26}$ Animals were maintained in a specific pathogen-free facility of Columbia University (New York, NY). Mice were genotyped using DNA extracted from tail biopsies (Qiagen, Valencia, CA) for allele-specific polymerase chain reaction. All animal experiments were approved by the Institutional Animal Care and Use Committee of Columbia University and conformed to the guidelines outlined in the National Institutes of Health Guide for Care and Use of Laboratory Animals.

\section{PanIN Mouse Model}

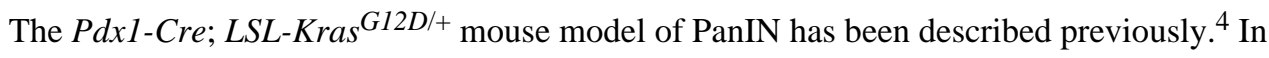
brief, the pancreas-specific promoter, $P d x l$, directs Cre recombinase-mediated excision of a floxed STOP cassette in pancreas progenitor cells, leading to the expression of the Kras ${ }^{\mathrm{G} 12 \mathrm{D}}$ 
mutation in mature pancreatic cell lineages. ${ }^{27}$ The mice develop early PanINs that progress to advanced PanINs and eventually to PDAC. To evaluate the impact of RAGE deletion on the development of PanIN, three lines of mice, Pdxl-Cre, LSL-Kras ${ }^{\mathrm{G} 12 \mathrm{D} /+}$, and $\mathrm{RAGE}^{-/-}$, were interbred to generate Pdxl-Cre; LSL-Kras ${ }^{G 12 D /+} ; R_{A G E^{-/-}}$mice and Pdxl-Cre; LSL$\mathrm{Kras}^{\mathrm{G12D/+}}$, RAGE $^{+/+}$controls. Specifically, the $R A G E$ null locus was bred into separate $\mathrm{Pdxl-Cre}$ and $\mathrm{LSL}-\mathrm{Kras}{ }^{\mathrm{Gl}}{ }^{\mathrm{D} /+}$ mouse lines to generate $\mathrm{Pdxl-Cre} ; \mathrm{RAGE}^{+/-}$and $\mathrm{LSL}$ $\mathrm{Kras}^{\mathrm{G} 12 \mathrm{D} /+}$; $\mathrm{RAGE}^{+/-}$mice. These mice were crossed as the final step to generate the experimental and control mice. Care was taken to cross-breed in a manner that ensured offspring were heterozygous for Pdxl-Cre and $\mathrm{Kras}^{\mathrm{G} 12 D}$.

\section{PDAC Mouse Model}

The Pdxl-Cre; LSL-Kras ${ }^{G 12 D /+} ;$ p16 $^{\text {Ink4a-/- }}$ mouse model of PDAC has been described previously..$^{5,6}$ The homozygous deletion of $p 16^{\operatorname{Ink} 4 a}$ promotes more rapid progression of PanINs to invasive PDAC. The model thus recapitulates the full spectrum of human PanINs and PDAC in a shorter period of time than the model described by Hingorani et al. ${ }^{4}$ (Qiu et al.; manuscript in revision). To evaluate the impact of $R A G E$ deletion on the development of PDAC, four lines of mice, Pdxl-Cre, LSL-Kras ${ }^{G 12 D /+}, p^{16} 6^{I n k 4 a-/-}$, and $R A G E^{-/-}$, were

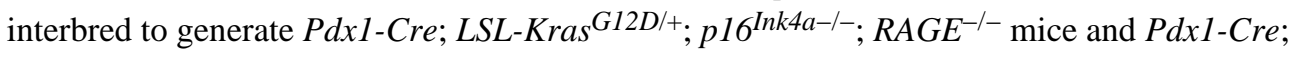
$L S L-\mathrm{Kras}^{G 12 D /+} ; \mathrm{pl6}^{\mathrm{Ink} 4 a-/-} ; R_{A G E^{+/+}}$controls. Specifically, the $p 16$ null locus and the $R A G E$ null locus were bred into separate Pdxl-Cre and $L S L-K r a s{ }^{G 12 D /+}$ mouse lines to

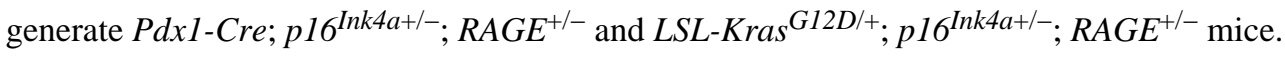
These mice were crossed as the final step to generate the experimental and control mice. Care was taken to crossbreed in a manner that ensured offspring were heterozygous for Pdxl-Cre and Kras ${ }^{G 12 D}$.

\section{Histopathologic Evaluation}

Formalin-fixed, paraffin-embedded pancreata were sectioned ( $5 \mu \mathrm{m}$ thick) and stained with H\&E. Sections (100 $\mu \mathrm{m}$ apart) of the entire pancreas were evaluated by a gastrointestinal pathologist (H. Remotti) blinded to the experimental groups. PanIN lesions were classified according to criteria recommended in the literature. ${ }^{28,29}$ To quantify the progression of PanIN lesions, ductal lesions were evaluated by a comprehensive scoring system that involved microscopic examination of all terminal ducts in the lobular units of the pancreas. A median of 38 lobular units were analyzed for each animal. Lobular units containing multiple ductal profiles were scored as normal or with respect to the highest degree of PanIN identified. The relative proportion of each PanIN lesion to the total number of ducts analyzed was recorded for each animal. Invasive carcinomas were evaluated by gross tumor dimensions with histologic confirmation.

\section{Immunohistochemistry}

Tissue sections were de-paraffinized in xylene and rehydrated in a graded ethanol series. Sections to be stained with the antibody to RAGE or HMGB1 were pretreated with trypsin for $20 \mathrm{~min}$. Sections to be stained with the antibody to $\mathrm{S} 100$ were heated by boiling in 10 $\mathrm{mM}$ citrate buffer, $\mathrm{pH} 6.0$ for $10 \mathrm{~min}$ followed by cooling at room temperature for $20 \mathrm{~min}$. All sections were further treated with $0.3 \% \mathrm{H}_{2} \mathrm{O}_{2}$ for 30 min before immunostaining. After 
blocking with 10\% normal goat serum (Vector Laboratories, Burlingame, CA), serial sections were stained with the rabbit polyclonal antibodies to RAGE (1:100; house), ${ }^{30}$ HMGB1 (1:50; ProteinTech Group Inc., Chicago, IL), and S100 (1:100; Abcam, Cambridge, MA), and were incubated overnight at $4{ }^{\circ} \mathrm{C}$ in a humidified chamber. After washing with phosphate-buffered saline (PBS), sections were incubated with biotinylated goat anti-rabbit immunoglobulin (1:200; Vector Laboratories Inc., Burlingame, CA) followed by peroxidase-conjugated avidin (Sigma, St. Louis, MO). Location of peroxidase-conjugates was revealed using 3-amino-9-ethylcarbazole as the chromogen.

\section{Statistics}

Categorical variables were compared using Fisher's exact test and reported as number and percentage (\%). To calculate the rate of duct dysplasia, loglinear Poisson regression was used to model the number of ducts displaying PanIN-2 lesions or greater as a function of the experimental group, with the offset equal to the natural log of the total number of ducts counted. When data were overdisbursed, a negative binomial regression model was fit in the same fashion. Survival probabilities were estimated using Kaplan-Meier methods, and strata were compared using the log-rank test. A $p$ value of less than 0.05 was considered statistically significant. Data analyses were performed with SAS software, Version 9.2 of the SAS System for Microsoft Windows (Copyright @ 2009 SAS Institute Inc., Cary, NC, USA).

\section{Results}

\section{RAGE and RAGE Ligand Expression}

Histologic examination of H\&E-stained sections of pancreata from Pdxl-Cre; LSLKras $^{\mathrm{G12D/+}}$; p16 ${ }^{\text {Ink4a-/- }}$ mice showed a spectrum of ductal neoplasia, ranging from PanIN-1 to invasive PDAC (Fig. 1). Representative sections of normal, dysplastic, and cancerous ducts revealed expression of RAGE, S100, and HMGB1 (Fig. 2).

\section{RAGE Deletion Inhibits PanIN Development in Pdx1-Cre; LSL-Kras ${ }^{\text {G12D/+ Mice }}$}

At 16 weeks of age, Pdxl-Cre; $L S L-\mathrm{Kras}^{G 12 D /+}$; $R A G E^{-/-}$mice (n=6) had a $67 \%$ lower rate of high-grade PanINs compared to $R A G E^{+/+}$controls $(n=6 ; p=0.0005)$. The $R A G E^{-/-}$mice also had a significantly lower incidence of high-grade PanINs compared to $R A G E^{+/+}$ controls $(5.1 \%$ vs. $15.3 \%, p=0.0003$; Fig. 3$)$

\section{RAGE Deletion Inhibits PanIN Development and Progression to PDAC in Pdx1-Cre; LSL- Kras $^{\mathrm{G} 12 \mathrm{D} /+} ;$ p16 $^{\text {Ink4a-/- Mice }}$}

At 12 weeks of age, Pdxl-Cre; LSL-Kras ${ }^{G 12 D /+} ; p^{16} 6^{I n k 4-/-} ; R A G E^{-/-}$mice $(n=11)$ had a $36.7 \%$ lower rate of high-grade PanINs compared to $R A G E^{+/+}$controls $(n=11 ; p=0.2069$;

Fig. 4a). The $R A G E^{-/-}$mice also had a significantly lower incidence of high-grade PanINs compared to $R A G E^{+/+}$controls $(11.3 \%$ vs. $19.9 \%, p=0.0075$; Fig. 4 b). Strikingly, the $P d x 1$ Cre; $L S L-K r a s^{G 12 D /+} ; p^{I n k 4 a-l-} ; R A G E^{-/-}$mice had more benign histopathology with no mouse harboring PDAC compared to $45.5 \%$ PDAC in $R A G E^{+/+}$controls $(p=0.0351$; Fig. 4c). 


\section{RAGE Deletion Prolongs Survival in Pdx1-Cre; LSL-Kras ${ }^{\text {G12D/+}}$; p16 ${ }^{\text {Ink4a-/- }}$ Mice}

To test the effect of genetic deletion of RAGE on survival, 12 Pdxl-Cre; LSL-Kras ${ }^{G 12 D /+}$;

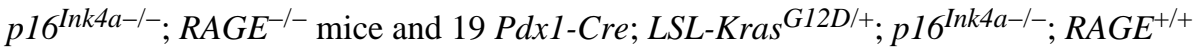
controls were aged and followed. The $R A G E^{-/-}$mice lived significantly longer than their $\mathrm{RAGE}^{+/+}$controls with median survivals of 21.9 and 13.0 weeks, respectively $(p=0.0051$; Fig. 5). Necropsy and pathologic analysis revealed that tumors were ductal adenocarcinomas with varied histologic patterns of high cytologic grade: glandular, solid spindle (sarcomatoid), or solid epithelioid (anaplastic). Often the greatest degree of cytologic atypia and pleomorphism was demonstrated in the epithelioid areas. PDAC in the $R A G E^{-/-}$mice tended to exhibit a greater percentage of glandular differentiation whereas PDAC in the $R A G E^{+/+}$controls tended to exhibit a greater percentage of more poorly differentiated components, characterized by diffuse infiltrate of spindle or epithelioid tumor cells (Fig. 6).

\section{Discussion}

Genetically engineered mouse models that recapitulate human disease are useful in the preclinical study of pancreatic carcinogenesis. ${ }^{31-34}$ Conditional KRAS transgenic models slowly develop a full range of PanINs with progression to PDAC after a prolonged latency. ${ }^{35}$ They are excellent models for the study of PanIN, but require lengthy time periods for the study of PDAC. When a second genetic alteration is added to the model, invasive disease develops more rapidly. Aguirre et al. ${ }^{6}$ reported that deletion of $p 16^{\operatorname{Ink} 4 a}$ cooperated with the activation of $\operatorname{Kras}^{G 12 D}$ to promote the malignant conversion of PanINs to PDAC. Given these data, we chose Pdxl-Cre; $L S L-K r a s{ }^{G 12 D /+}$ mice to model the development of PanIN and Pdxl-Cre; LSL-Kras ${ }^{G 12 D /+} ; p_{16}^{\text {Ink4a-I- }}$ mice to model the progression to PDAC.

Several reports in the literature have investigated possible targets for intervention in pancreatic cancer by using variations on the conditional Kras ${ }^{G 12 D}$ transgenic mouse model. Mohammed et al. ${ }^{36}$ used $p 48^{\mathrm{Cre} /+}$; $L S L-K r a s^{G 12 D /+}$ mice to study the efficacy of gefitinib, an epidermal growth factor receptor (EGFR) inhibitor, on the development of PanIN. They treated the mice with gefitinib and found significant suppression of PanIN development and progression to PDAC, highlighting EGFR as a potential target for chemoprevention of pancreatic cancer. Funahashi et al. ${ }^{27}$ used Pdxl-Cre; $L S L-K r a s{ }^{G 12 D /+}$ mice to study the effects of nimesulide, a selective COX-2 inhibitor, on the development of PanIN. They reported that pancreatic ducts in treated mice displayed 70\% PanIN-1, 10\% PanIN-2, and 0\% PanIN-3 compared to 50\%, 30\%, and 10\%, respectively, in controls. COX-2 inhibition thus delayed the progression of PanIN, suggesting a role for anti-inflammatory agents in pancreatic cancer chemoprevention.

Another potential target for chemoprevention of pancreatic cancer is RAGE. Found on both inflammatory and epithelial tumor cells, RAGE has been implicated in cellular and molecular pathways that promote inflammation and carcino-genesis. ${ }^{10-17}$ It is known that pancreatic cancer cells express RAGE and its ligands, and there is mounting evidence that the ligand-RAGE axis plays an important and complex role in the biology of pancreatic cancer. Using pancreatic cancer cell lines, Arumugam et al. ${ }^{37}$ demonstrated that, via interaction with RAGE, S100P promotes pancreatic cancer cell proliferation, survival, and 
invasion. Whiteman et al. ${ }^{21}$ suggested that invasion of pancreatic cancer cells occurs via S100P-mediated cytoskeletal changes. In further studies, Arumugam et al. ${ }^{38}$ demonstrated that inhibition of RAGE interaction with S100P led to enhanced anti-tumor activity of gemcitabine in a xenograft model of pancreatic cancer. Blockade of S100P interaction with RAGE by a RAGE antagonist peptide inhibited these biological effects, suggesting that interference with the ligand-RAGE axis may be a novel approach for pancreatic cancer treatment.

Given these data from pancreatic cell lines, we endeavored to investigate the role of RAGE in pancreatic cancer tumorigenesis in an orthotopic mouse model. First, to confirm that RAGE and its ligands were relevant to the model, we stained representative sections of pancreata from the conditional $\mathrm{Kras}^{G 12 D}$ model and demonstrated the presence of RAGE and its ligands S100 and HMGB1 in the neoplastic pancreatic ductal epithelium. Next, we used Pdxl-Cre; $L S L-K r a s{ }^{G 12 D /+}$ and $R A G E^{-/-}$mice to investigate the role of RAGE on PanIN development. By breeding the RAGE null locus into the model, we were able to demonstrate a significant decrease in incidence and rate of PanIN-2 and PanIN-3 development in 16-week-old mice. We chose 16 weeks of age to allow the mice sufficient time to develop a spectrum of precursor lesions, but not so much time as to develop invasive disease. To investigate the role of RAGE on PanIN progression to PDAC, we used $P d x 1$ Cre; LSL-Kras ${ }^{G 12 D /+} ; p_{16}^{\text {Ink4a-/- }}$ and $R A G E^{-/-}$mice. We bred the RAGE null locus into the model and demonstrated a significant decrease in incidence of PanIN-2 and PanIN-3 development with no progression to PDAC in 12-week-old mice. We chose 12 weeks of age to allow adequate time for progression to PDAC. Importantly, this difference in disease progression correlated with improved mouse survival. To our knowledge, this study represents the first use of genetic RAGE deletion in a conditional Kras ${ }^{G 12 D}$ transgenic mouse model.

Our study demonstrates a clear, RAGE-mediated phenomenon. In light of recent literature, we can hypothesize that RAGE and its ligands facilitate the development of an inflammatory tumor microenvironment that promotes carci-nogenesis in the pancreatic ducts. The inflammatory cytokine, HMGB1, for example, is released upon pancreatic tumor cell death and, depending on its redox status, promotes tumor cell survival and resistance to chemotherapeutic agents. ${ }^{39,40}$ Building on this work, Kang et al. ${ }^{9}$ established a direct link between inflammatory mediators in the tumor microenvironment and resistance to apoptosis in pancreatic cancer cells. They showed that targeted knockdown of RAGE significantly increased tumor cell death via a p53-dependent pathway and that forced over-expression of RAGE promoted tumor cell survival via decreased phosphorylation of the mammalian target of rapamycin. They thus suggested a new paradigm in tumor biology whereby proinflammatory factors aggregate in the tumor microenvironment and interact with RAGE to increase programmed cell survival and decrease programmed cell death. It is plausible that lack of RAGE-mediated inflammatory signaling within the pancreatic ductal epithelium in our Pdxl-Cre; LSL-Kras ${ }^{G 12 D /+} ;$ RAGE$^{-/-}$and Pdxl-Cre; LSL-Kras ${ }^{G 12 D /+} ;$ pl $^{\text {Ink4a-l-; }}$; $R A G E^{-/-}$mice contributes to less aggressive pathology and prolonged survival. Additional investigation into differences in RAGE signaling within pancreatic ductal epithelial cells 
versus inflammatory cells within the tumor microenvironment may help further elucidate the role of RAGE signaling in the pathogenesis of pancreatic cancer.

\section{Conclusion}

This study provides evidence that RAGE signaling plays an important role in pancreatic tumorigenesis. Using established murine models of PanIN and PDAC, we showed that loss of function via genetic deletion of RAGE inhibited PanIN development in Pdxl-Cre; $L S L$ $\mathrm{Kras}^{\mathrm{G} 12 \mathrm{D} /+} ; \mathrm{RAGE}^{-/-}$mice and progression to PDAC in Pdxl-Cre; LSL-Kras ${ }^{G 12 D /+}$; p16 $6^{\text {Ink4a-I--}} ; R A G E^{-/-}$mice. Importantly, the inhibitory effects significantly prolonged mouse survival. Taken together, these data link RAGE to the development and progression of premalignant pancreatic ductal neoplasia. Further cellular and molecular work is needed to target the ligand-RAGE axis for possible early intervention and prophylaxis in patients at risk for developing pancreatic cancer.

\section{Acknowledgments}

This work was generously supported by the I.W. Foundation and an institutional Ruth L. Kirschstein National Research Service Award (T32 HL 007854-14).

\section{References}

1. Jemal A, Siegel R, Xu J, Ward E. Cancer statistics, 2010. CA cancer J Clin. 2010; 60:277-300. [PubMed: 20610543]

2. Maitra A, Fukushima N, Takaori K, Hruban RH. Precurors to invasive pancreatic cancer. Adv Anat Pathol. 2005; 12:81-91. [PubMed: 15731576]

3. Hruban RH, Goggins M, Parsons J, Kern SE. Genetic progression in the pancreatic ducts. Am J Pathol. 2000; 156:1821-1825. [PubMed: 10854204]

4. Hingorani SR, Petrcoin EF, Maitra A, Rajapakse V, King C, Jacobetz MA, Ross S, Conrads TP, Veenstra TD, Hitt BA, Kawaguchi Y, Wright CVE, Hruban RH, Lowy AM, Tuveson DA. Preinvasive and invasive ductal pancreatic cancer and its early detection in the mouse. Cancer cell. 2003; 4:437-450. [PubMed: 14706336]

5. Bardeesy N, Aguirre AJ, Chu GC, Cheng KH, Lopez LV, Hezel AF, Feng B, Brennan C, Weissleder R, Mahmood U, Hanahan D, Redston MS, Chin L, DePinho RA. Both p16 ${ }^{\text {Ink4a }}$ and the p19 Arf - p53 pathway constrain progression of pancreatic adenocarcinoma in the mouse. PNAS. 2006; 103:5947-5952. [PubMed: 16585505]

6. Aguirre AJ, Bardeesy N, Sinha M, Lopez L, Tuveson DA, Horner J, Redston MS, DePinho RA. Activated Kras and Ink4a/Arf deficiency cooperate to produce metastatic pancreatic ductal adenocarcinoma. Genes \& Dev. 2003; 17:3112-3126. [PubMed: 14681207]

7. Bardessy N, Morgan J, Sinha M, Signoretti S, Srivastava S, Loda M, Merlino G, DePinho RA. Obligate roles for p16Ink4a and p19Arf-p53 in the suppression of murine pancreatic neoplasia. Mol Cell Biol. 2002; 22:635-643. [PubMed: 11756558]

8. Han SH, Kim YH, Mook-Jung I. RAGE: The beneficial and deleterious effects by diverse mechanisms of actions. Mol Cells. 2011; 31:91-97. [PubMed: 21347704]

9. Kang R, Tang D, Schapiro NE, Livesey KM, Farkas A, Loughran P, Bierhaus A, Lotze MT, Zeh HJ. The receptor for advanced glycation end products (RAGE) sustains autophagy and limits apoptosis promoting pancreatic tumor cell survival. Cell Death Differ. 2010; 17:666-676. [PubMed: 19834494]

10. Mantovani A, Allavena P, Sica A, Balkwill F. Cancer-related inflammation. Nature. 2008; 454:436-444. [PubMed: 18650914] 
11. Kim S, Takahashi H, Lin WW, Descargues P, Grivennikov S, Kim Y, Luo JL, Karin M. Carcinoma-produced factors activate myeloid cells through TLR2 to stimulate metastasis. Nature. 2009; 457:102-107. [PubMed: 19122641]

12. Schmidt AM, Yan SD, Yan SF, Stern DM. The multiligand receptor RAGE as a progression factor amplifying immune and inflammatory responses. J Clin Invest. 2001; 108:949-955. [PubMed: 11581294]

13. Logsdon CD, Fuentes MK, Huang EH, Arumugam T. RAGE and RAGE ligands in cancer. Curr Mol Med. 2007; 7:777-789. [PubMed: 18331236]

14. Riehl A, Németh J, Angel P, Hess J. The receptor RAGE: bridging inflammation and cancer. Cell Comm Sig. 2007; 7:12.

15. Rojas A, Figueroa H, Morales E. Fueling inflammation at tumor microenvironment: the role of multiligand/RAGE axis. Carcino-genesis. 2010; 31:334-341.

16. Ramasamy R, Yan SF, Schmidt AM. RAGE: therapeutic target and biomarker of the inflammatory response-the evidence mounts. J Leukoc Biol. 2009; 86:505-512. [PubMed: 19477910]

17. Sims GP, Rowe DC, Rietdijk ST, Herbst R, Coyle AJ. HMGB1 and RAGE in inflammation and cancer. Annu Rev Immunol. 2010; 28:367-388. [PubMed: 20192808]

18. Takada M, Koizumi T, Toyama H, Suzuki Y, Kuroda Y. Differential expression of RAGE in human pancreatic carcinoma cells. Hepatogastroenterology. 2001; 48:1577-1578. [PubMed: 11813576]

19. Takada M, Hirata K, Ajiki T, Suzuki Y, Kuroda Y. Expression of receptor for advanced glycation end products (RAGE) and MMP-9 in human pancreatic cancer cells. Hepatogastroenterology. 2004; 51:928-930. [PubMed: 15239215]

20. Krechler T, Jachymova M, Mestek O, Zak A, Zima T, Kalousova M. Soluble receptor for advanced glycation end-products (sRAGE) and polymorphisms or RAGE and glyoxalase I genes in patients with pancreas cancer. Clin Biochem. 2010; 43:882-886. [PubMed: 20398646]

21. Whiteman HJ, Weeks ME, Dowen SE, Barry S, Timms JF, Lemoine NR, Crnogorac Jurcevic T. The role of $\mathrm{S} 100 \mathrm{P}$ in the invasion of pancreatic cancer cells is mediated through cytoskeletal changes and regulation of cathepsin D. Cancer Res. 2007; 67:8633-8642. [PubMed: 17875703]

22. DiNorcia J, Moroziewicz DN, Ippagunta N, Lee MK, Foster M, Rotterdam HZ, Bao F, Zou YS, Yan SF, Emond J, Schmidt AM, Allendorf JD. RAGE signaling significantly impacts tumorigenesis and hepatic tumor growth in murine models of colorectal carcinoma. J Gastrointest Surg. 2010; 14:1680-90. [PubMed: 20824364]

23. Jackson EL, Willis N, Mercer K, Bronson RT, Crowley D, Montoya R, Jacks T, Tuveson DA. Analysis of lung tumor initiation and progression using conditional expression of oncogenic Kras. Genes \& Dev. 2001; 15:3243-3248. [PubMed: 11751630]

24. Sharpless NE, Bardeesy N, Lee KH, Carrasco D, Castrillon DH, Aguirre AJ, Wu EA, Horner JW, DePinho RA. Loss of $\mathrm{p} 16^{\text {Ink4a }}$ with retention of $\mathrm{p} 19^{\text {Arf }}$ predisposes mice to tumorigenesis. Nature. 2001; 413:86-91. [PubMed: 11544531]

25. Wendt TM, Tanji N, Guo J, Kislinger TR, Qu W, Lu Y, Bucciarelli LG, Rong LL, Moser B, Markowitz GS, Stein G, Bierhaus A, Liliensiek B, Arnold B, Nawroth PP, Stern DM, D'Agati VD, chmidt AM. RAGE drives the development of glomerulosclerosis and implicates podocyte activation in the pathogenesis of diabetic nephropathy. Am J Pathol. 2003; 162:1123-1137. [PubMed: 12651605]

26. Sakaguchi T, Yan SF, Yan SD, Belov D, Rong LL, Sousa M, Andrassy M, Marso SP, Duda S, Arnold B, Liliensiek B, Nawroth PP, Stern DM, Schmidt AM, Naka Y. Central role of RAGEdependent neointimal expansion in arterial restenosis. J Clin Invest. 2003; 111:959-972. [PubMed: 12671045]

27. Funahashi H, Satake M, Dawson D, Huynh NA, Reber HA, Hines OJ, Eibl G. Delayed progression of pancreatic intraepithelial neoplasia in a conditional Kras ${ }^{6} 12 \mathrm{D}$ mouse model by a selective cyclooxygenase-2 inhibitor. Cancer Res. 2007; 67:7068-7071. [PubMed: 17652141]

28. Hruban RH, Rustgi AK, Brentnall TA, Tempero MA, Wright CV, Tuveson DA. Pancreatic cancer in mice and man: the Penn Workshop 2004. Cancer Res. 2006; 66:14-7. [PubMed: 16397208]

29. Hruban RH, Adsay NV, Albores-Saavedra J, Anver MR, Biankin AV, Boivin GP, Furth EE, Furukawa T, Klein A, Klimstra DS, Kloppel G, Lauwers GY, Longnecker DS, Luttges J, Maitra 
A, Offerhaus GJ, Perez-Gallego L, Redston M, Tuveson DA. Pathology of genetically engineered mouse models of pancreatic exocrine cancer: consensus report and recommendations. Cancer Res. 2006; 66:95-106. [PubMed: 16397221]

30. Taguchi A, Blood DC, del Toro G, Canet A, Lee DC, Qu W, Tanji N, Lu Y, Lalla E, Fu C, Hofmann MA, Kislinger T, Ingram M, Lu A, Tanaka H, Hor O, Ogawa S, Stern DM, Schmidt AM. Blockade of amphoterin/RAGE signaling suppresses tumor growth and metastases. Nature. 2001; 405:354-360. [PubMed: 10830965]

31. Shi G, Shu L, Sun Y, Bettencourt R, Damsz B, Hruban RH, Konieczny SF. Loss of the acinarrestricted transcription factor Mist1 accelerates Kras-induced pancreatic intraepithelial neoplasia. Gastroenterology. 2009; 136:1328-1378. [PubMed: 19138686]

32. Lee KE, Bar-Sagi D. Oncogenic KRas suppresses inflammation-associated senescence of pancreatic ductal cells. Cancer Cell. 2010; 18:448-458. [PubMed: 21075310]

33. Fendrich V, Schneider R, Maitra A, Jacobsen ID, Opfermann T, Bartsch DK. Detection of precursor lesions of pancreatic adenocarcinoma in PET-CT in a genetically engineered mouse model of pancreatic cancer. Neoplasia. 2011; 13:180-186. [PubMed: 21403843]

34. Rowley M, Ohashi A, Mondal G, Mills L, Yang L, Zhang L, Sundsbak R, Shapiro V, Muders MH, Smyrk T, Couch FJ. Inactivation of Brca2 promotes Trp53-associated but inhibits KrasG12Ddependent pancreatic cancer development in mice. Gastroenterology. 2011; 140:1303-1313. [PubMed: 21199651]

35. Hill R, Calvopina JH, Kim C, Wang Y, Dawson DW, Donahue TR, Dry S, Wu H. PTEN loss accelerates KrasG12D-induced pancreatic cancer development. Cancer Res. 2010; 70:2114-7124.

36. Mohammed A, Janakiram NB, Li Q, Madka V, Ely M, Lightfoot S, Crawford H, Steele VE, Rao $\mathrm{CV}$. The epidermal growth factor receptor inhibitor Gefitinib prevents the progression of pancreatic lesions to carcinoma in a conditional LSL-Kras ${ }^{\mathrm{G} 12 \mathrm{D} /+}$ transgenic mouse model. Cancer Prev Res. 2010; 3:1417-1426.

37. Arumugam T, Simeone DM, Van Golen K, Logsdon CD. S100P promotes pancreatic cancer growth, survival, and invasion. Clin Cancer Res. 2005; 11:5356-5364. [PubMed: 16061848]

38. Arumugam T, Ramachandran V, Logsdon CD. Effect of cromolyn on S100P interactions with RAGE and pancreatic cancer growth and invasion in mouse models. J National Cancer Inst. 2006; 98:1806-1818.

39. Kostova N, Zlateva S, Ugrinova I, Pasheva E. The expression of HMGB1 protein and its receptor RAGE in human malignant tumors. Mol Cell Biochem. 2010; 337:251-258. [PubMed: 19876719]

40. Tang D, Lotze MT, Zeh HJ, Kang R. The redox protein HMGB1 regulates cell death and survival in cancer treatment. Autophagy. 2010; 16:1181-1183. [PubMed: 20861675] 


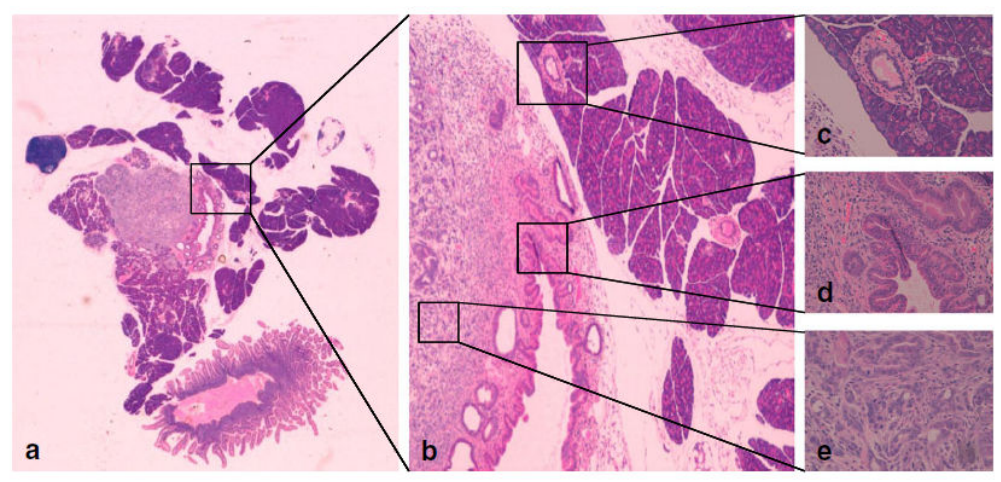

Fig. 1.

H\&E-stained sections of the pancreas from a Pdxl-Cre; LSL-Kras ${ }^{G 12 D /+} ;$ p16 Ink4a-I- mouse at 12 weeks of age demonstrate a spectrum of ductal neoplasia. $\mathbf{a} \times 10$ magnification shows an entire pancreas. $\mathbf{b} \times 100$ magnification of the indicated section demonstrates pancreatic ducts with varying degrees of dysplasia. $\mathbf{c} \times 200$ magnification of the indicated section demonstrates a PanIN-1 lesion. $\mathbf{d} \times 200$ magnification of the indicated section demonstrates ducts with PanIN-2 and PanIN-3 lesions. $\mathbf{e} \times 200$ magnification of the indicated section demonstrates PDAC 

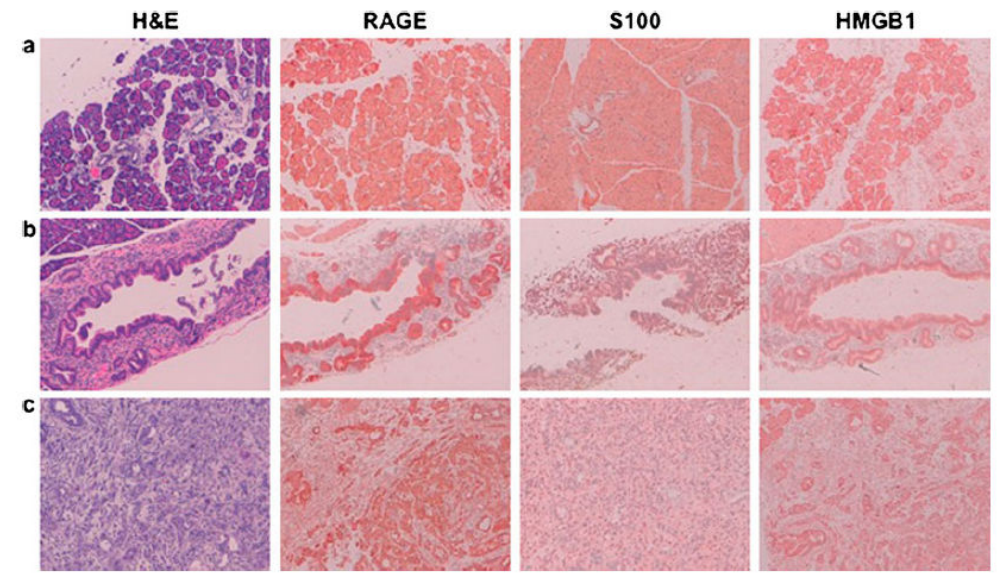

Fig. 2.

RAGE and its ligands, S100 and HMGB1, are expressed in the pancreatic ductal epithelium of a Pdxl-Cre; LSL-Kras ${ }^{\mathrm{Gl} D /+} ; \mathrm{pl}^{\mathrm{Ink} 4 a-/-}$ mouse at 12 weeks of age. H\&E-stained sections demonstrate normal and dysplastic ductal architecture. Immunohistochemical staining of serial sections demonstrates expression of RAGE, S100, and HMGB1. a normal pancreatic ducts. b PanIN2 and PanIN3. c PDAC 
a

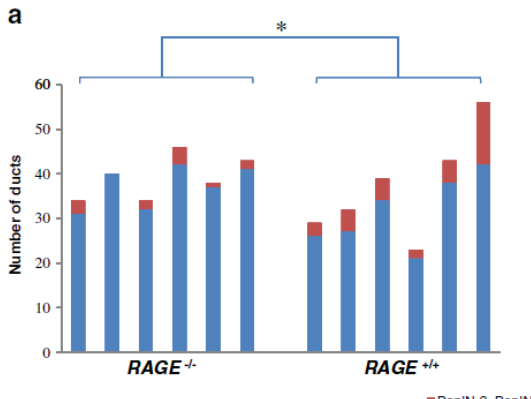

b

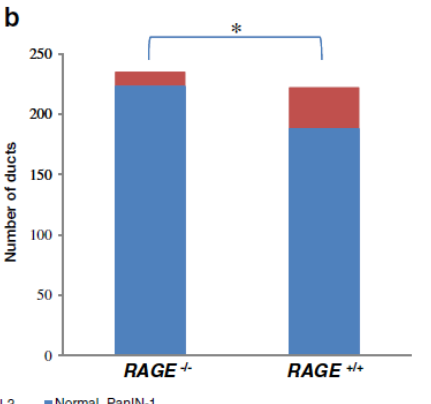

Fig. 3.

RAGE deletion inhibits PanIN development in PdxI-Cre; LSL-Kras ${ }^{G 12 D /+}$ mice. Pdxl-Cre; $L S L-K r a s^{G 12 D /+} ; R A G E^{-/-}$mice $(n=6)$ had a significantly lower rate and incidence of highgrade PanINs compared to $R A G E^{+/+}$controls $(n=6)$ at 16 weeks of age. a Proportion of PanIN-2 and PanIN-3 ducts compared to normal and PanIN-1 ducts for each mouse are shown. b Proportion of PanIN-2 and PanIN-3 ducts compared to normal and PanIN-1 ducts for all mice in each group are shown. ${ }^{*} p<0.01$ 
a

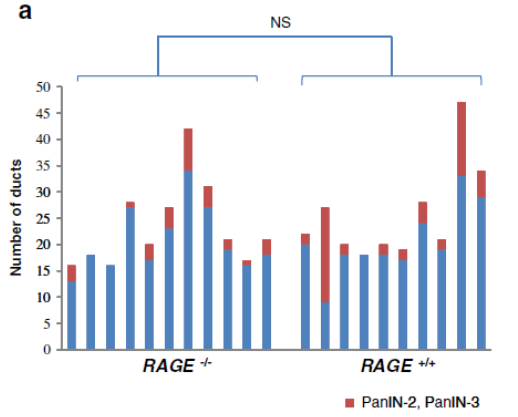

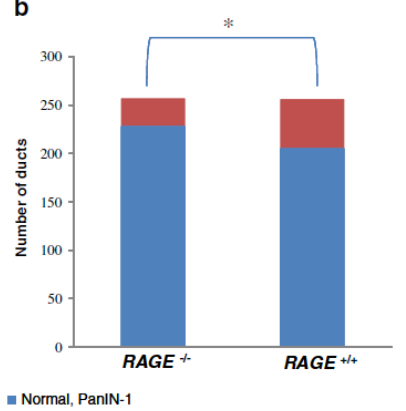

c

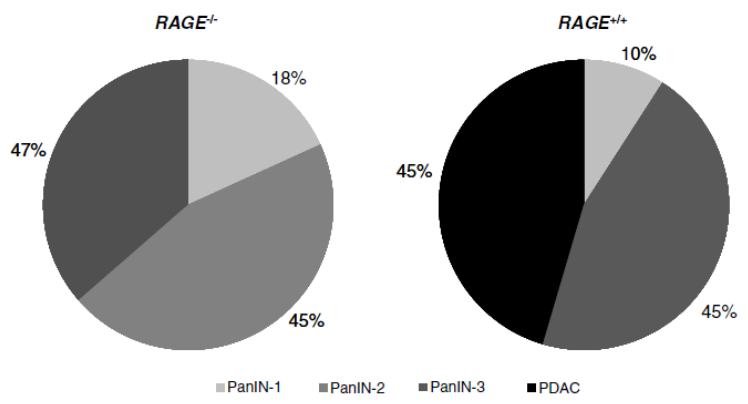

Fig. 4.

$R A G E$ deletion inhibits development and progression of ductal neoplasia in Pdxl-Cre; $L S L$ -

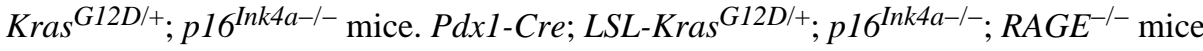
$(n=11)$ had a decreased rate and a significantly lower incidence of high-grade PanINs compared to $R A G E^{+/+}$controls $(n=11)$ at 12 weeks of age. a Proportion of PanIN-2 and PanIN-3 ducts compared to normal and PanIN-1 ducts for each mouse are shown. One mouse in the $R A G E^{+/+}$group had no normal ducts or PanIN lesions because of diffuse PDAC and therefore is not represented. b Proportion of PanIN-2 and PanIN-3 ducts compared to normal and PanIN-1 ducts for all mice in each group are shown. $\mathbf{c} P d x 1-C r e$; LSL-Kras ${ }^{G 12 D /+}$; pl6 $^{\text {Ink } 4 a-/-} ; R^{2} G E^{-/-}$mice had more benign histopathology with no mouse harboring PDAC compared to $45.5 \%$ PDAC in $\mathrm{RAGE}^{+/+}$controls. Mice are classified according to the highest grade lesion seen on histopathologic examination. NS=not significant, ${ }^{*} p<0.01$ 


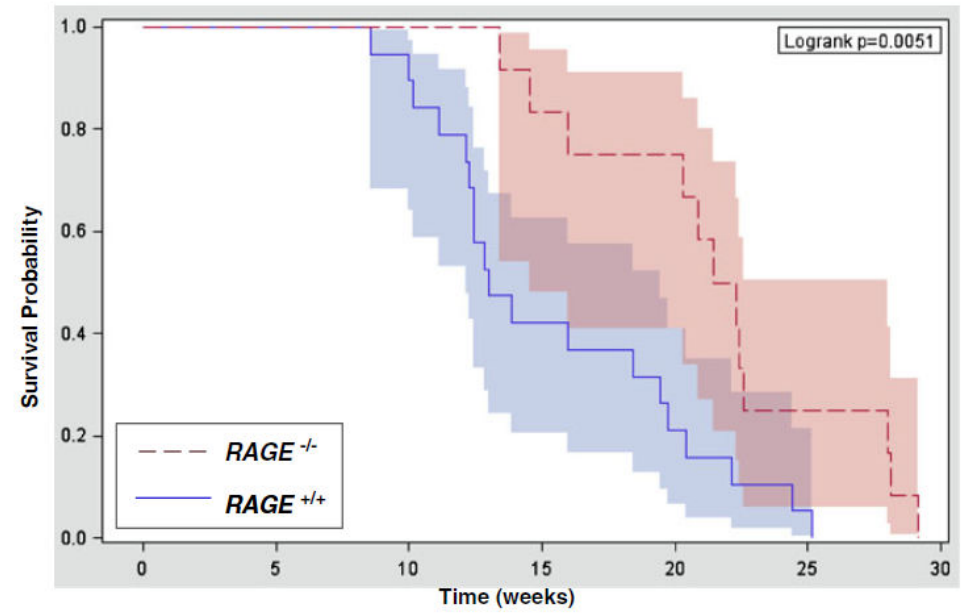

Fig. 5.

$R A G E$ deletion prolongs survival in Pdxl-Cre; LSL-Kras ${ }^{G 12 D /+} ; p^{16} 6^{I n k 4 a-/-}$ mice. Twelve PdxI-Cre; LSL-Kras ${ }^{G 12 D /+} ;$ pl6 $^{\text {Ink4a-l-} ; ~ R A G E^{-/-} \text {mice and } 19 \text { PdxI-Cre; LSL-Kras }}{ }^{\text {G12D/+; }}$; pl6 ${ }^{\text {Ink } 4 a-I_{-}} ; R A G E^{+/+}$controls were aged and followed. The $R A G E^{-/-}$mice lived significantly longer than their $R A G E^{+/+}$controls with median survivals of 21.9 weeks and 13.0 weeks, respectively $(p=0.0051)$ 


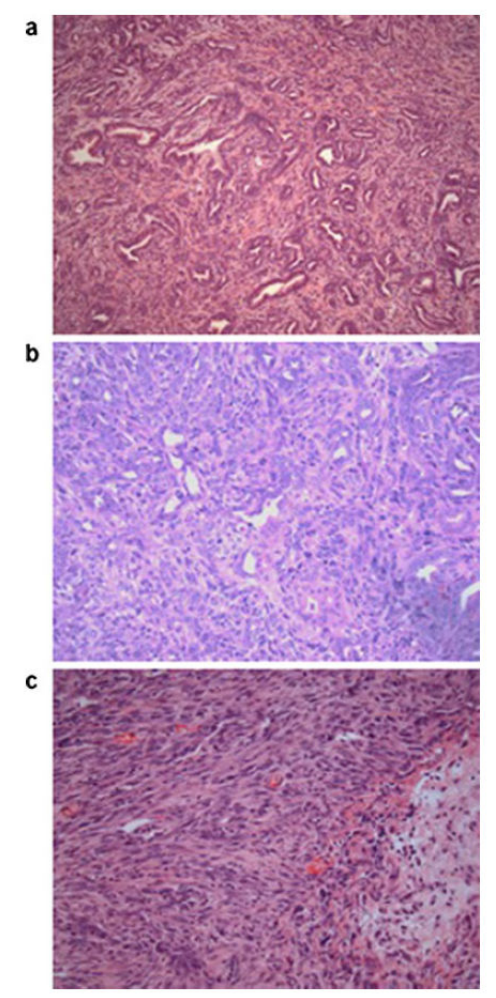

Fig. 6.

$\mathrm{H} \&$ E-stained sections from pancreata obtained at necropsy from $P d x 1-C r e ; L S L$ -

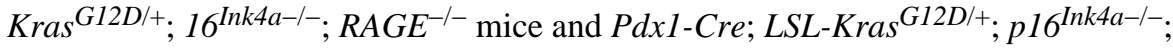
$R A G E^{+/+}$controls. Tumors were ductal adenocarcinomas with varied histologic patterns. a glandular; b solid spindle (sarcomatoid); c solid epithelioid (anaplastic) 